\title{
The Gemological Characteristics of PipI Pearls Reportedly from Pinctada maculata
}

Nanthaporn Nilpetploy, Kwanreun Lawanwong, and Promlikit Kessrapong

Pipi pearls originating from the bivalve mollusk Pinctada maculata are usually small natural pearls with a desirable and variable range of moderate to strong colors. This study details their characteristic features, including their internal structures and the spectroscopic data that may aid in their identification. The samples were examined by microradiography to reveal the range of internal structures found within these natural pearls. Spectroscopic studies were also employed using conventional gemological methods such as ultravioletvisible (UV-Vis) reflectance, Raman, and photoluminescence (PL) spectroscopy. The spectroscopic results showed some characteristic patterns such as a distinct absorption feature around $495 \mathrm{~nm}$ in the UV-Vis spectra and peaks at 1380 and $1540 \mathrm{~cm}^{-1}$ in the Raman spectra. The spectral features show some similarities to other mollusk species within the same family but may still assist gemologists in separating, to some degree, Pinctada maculata species from their relatives.

In the Polynesian language, pipi means "small" or "tiny" and is used to refer to the small, predominantly yellow or "golden" pearls that originate from the bivalve mollusk Pinctada maculata (Gould, 1846). As the smallest mollusk species in the Pinctada genus, Pinctada maculata rarely exceeds $5 \mathrm{~cm}$ when measured in the anterioposterior or dorsoventral positions. The mollusk lives in the Indo-Pacific Ocean, mostly around French Polynesia and the Cook Islands, where they are often found in association with the Pinctada margaritifera mollusk species (Strack, 2006). Pearls from Pinctada maculata often form in round to near-round shapes. As the name implies, the small shells produce small pearls that rarely

See end of article for About the Authors and Acknowledgments.

Gems \& GemOlogr, Vol. 54, No. 4, pp. 418-427,

http://dx.doi.org/10.5741/GEMS.54.4.418

(C) 2018 Gemological Institute of America exceed $8 \mathrm{~mm}$ in diameter (Krzemnicki, 2014). Based on GIA's experience, $6 \mathrm{~mm}$ or under is more typical of the species.

Pipi pearls are known to occur as natural pearls rather than cultured and, compared with other Pinctada species, are deemed rare. One report recorded only one gem-quality pearl found from a total of 355 mollusks (Passfield, 1997). In 1950, several cultured pearl experiments using Pinctada maculata reportedly took place but were unsuccessful (Segura et al., 2014). In the late 1990s, a few Pinctada maculata cultured blister pearls resulted from experiments in the waters off Penrhyn, an island in the northern atoll of the Cook Islands (Kessrapong et al., 2017). The nacre covering the bead nuclei did not fully overgrow the nuclei, however, and this attempt was not very successful. Some reports suggest that the Pinctada maculata mollusk is not abundant enough for

\section{In Brief}

- Pearls originating from the Pinctada maculata mollusk are rare and no known commercial cultured pearl production has been reported.

- Previous studies on pipi pearls were less comprehensive than this work and the results provide some information on the characteristics that may assist in the identification of pearls produced by the Pinctada maculata mollusk.

- The combination of the nature of a pearl's internal structure via microradiography and its spectroscopic results (ultraviolet visible (UV-Vis) reflectance, Raman, and photoluminescence (PL) spectroscopy) help indicate whether a pearl formed in a Pinctada maculata mollusk or another species.

commercial exploitation. Local regulations also protect them from being harvested by foreigners, further limiting the chances of cultured pearl production (Buscher, 1999). Given the limited documentation of Pinctada maculata cultured pearls, it is almost certain that all pearls currently fished from the species are natural pearls. 


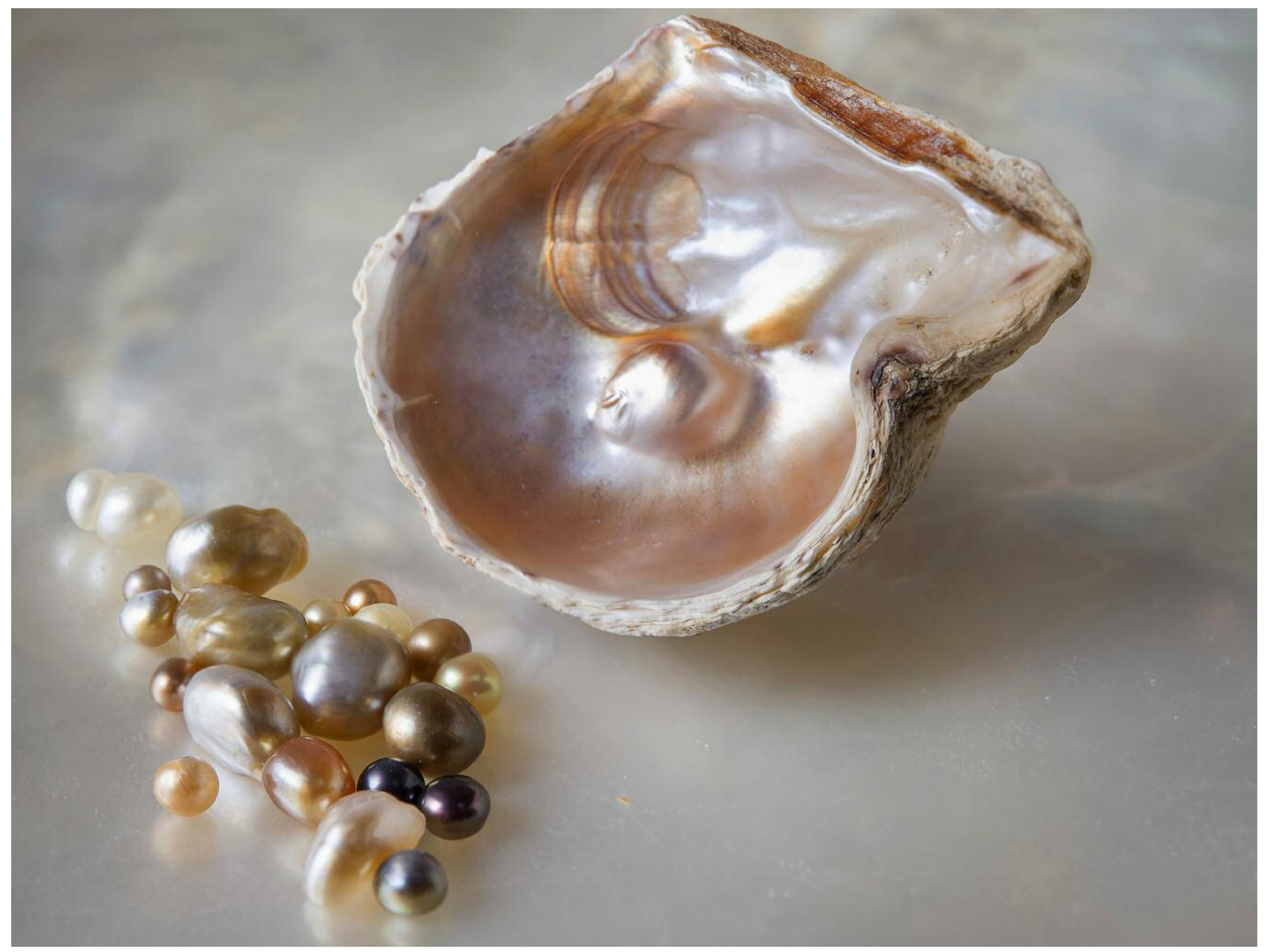

Figure 1. Pinctada maculata pearls alongside a Pinctada maculata mollusk valve with an attached blister pearl. The pearls range from $2.20 \mathrm{~mm}$ to $6.49 \times 4.83 \times 4.49 \mathrm{~mm}$, and the shell measures approximately $28.54 \times 26.50 \mathrm{~mm}$. Photo by Nuttapol Kitdee.

The spectroscopic data of Pinctada maculata shells and pearls appear to show some characteristic features that would help with their identification. While some previous work on the spectra of Pinctada maculata pearls has been undertaken (Segura et al., 2014), the results were inconclusive and could not specify the mollusk. The authors decided to pursue this study to record the characteristic features of reported Pinctada maculata pearls in order to share the data with the wider gemological community.

\section{MATERIALS AND METHODS}

GIA's Bangkok laboratory received 31 pearl samples that were claimed to be natural Pipi pearls originating from Pinctada maculata mollusks. One shell sample included an attached blister or blister pearl (figure 1). The pearls varied widely in color and exhibited a range of different tones. Colors within the group included white, cream, yellow-some of strong saturation, referred to as "golden" in the trade (GIA Pearl Grading Color Reference Charts, 2000)and yellow-orange to dark brown. Their sizes ranged from $2.22 \times 2.20 \mathrm{~mm}$ to $6.49 \times 4.83 \times 4.49 \mathrm{~mm}$, and their weights ranged from 0.06 to $1.00 \mathrm{ct}$. The shell measured approximately $28.54 \times 26.50 \mathrm{~mm}$ and weighed 5.04 grams. As indicated by the measurements, some of the samples fell within the size range known in the trade as "seed pearls." This term is usually applied to very small natural pearls between two and three millimeters when sieved (CIBJO, 2016).

Real-time microradiography (RTX) analysis was performed on the samples in three orientations using a Pacific Industries (PXI) GenX 90 X-ray system with 4 micron microfocus, $90 \mathrm{kV}$ voltage, and $0.18 \mathrm{~mA}$ current X-ray source with an exposure time of 200- 
350 milliseconds per frame, and a PerkinElmer 1512 $4 " / 2$ " dual-view flat panel detector with maximum 128 frames average and 74.8 micropixel pitch with $1944 \times 1536$ pixel resolution. Ultraviolet-visible (UVVis) spectra were obtained using an Agilent Cary 60 spectrophotometer with a custom-made GIA integrated sphere diffuse reflectance accessory (DRA) incorporating an $80 \mathrm{~Hz}$ xenon flash lamp source. Spectra were recorded in the $200-800 \mathrm{~nm}$ range with a data interval set at $1.0 \mathrm{~nm}$ and a $1.5 \mathrm{~nm}$ fixed spectral bandwidth and scan rate of $184.62 \mathrm{~nm} / \mathrm{min}$ over a $3.5 \mathrm{~mm}^{2}$ area. Raman and photoluminescence (PL) spectra were collected using a Renishaw inVia Reflex micro-Raman spectrometer system with a $50 \times$ magnification Leica objective lens and a $514 \mathrm{~nm}$ argonion laser. A laser power of $50 \mathrm{~mW}$ was used directly on the samples, and the system was calibrated using the standard internal silicon $520 \mathrm{~cm}^{-1}$ method. The Rayleigh radiation was blocked using edge filters. The laser was set at $100 \%$ power with three accumulations and an exposure time of 10 seconds with a grating of 1800 grooves $/ \mathrm{mm}$. PL spectra were collected with the laser power set at 50\% with one accumulation and an exposure time of 15 seconds with a grating of 1200 grooves $/ \mathrm{mm}$. The fluorescence reactions of the pearls were observed under UV radiation using a GIA-designed long-wave UV unit with a 4-watt UV lamp emitting $365 \mathrm{~nm}$ radiation. A GIA binocular gemological microscope was used to observe surface structures, determine the nature of the color (namely natural or artificial deposition), and assist with the detection of any other potential treatments.

\section{RESULTS}

Internal Structures. Pearls are composed of $\mathrm{CaCO}_{3}$ in the form of aragonite or calcite, conchiolin (an organic component), and water, as well as other residual substances (Southgate and Lucas, 2008). The radiopacity of the main $\mathrm{CaCO}_{3}$ component and the

Figure 2. Macro images of nine pearls (A-I, left column) weighing 0.11-0.97 ct. Photos by Sasithorn Engniwat. The RTX results for six pearls ( $A-F$, right column) revealed natural internal structures, typical of many nacreous pearls, while the structures of the other three pearls (G-I, right column) showed some features that might raise suspicion, such as seed-like features $(G-H$, green arrows) and off-round cores. Radial structure is evident in the organic-rich area of pearl I, and the blue arrows indicate the twin cores, one of which is ovoid. Spectroscopic analysis was also carried out on pearls $B$, $D$, and G (labeled P593, P587, and P588, respectively).
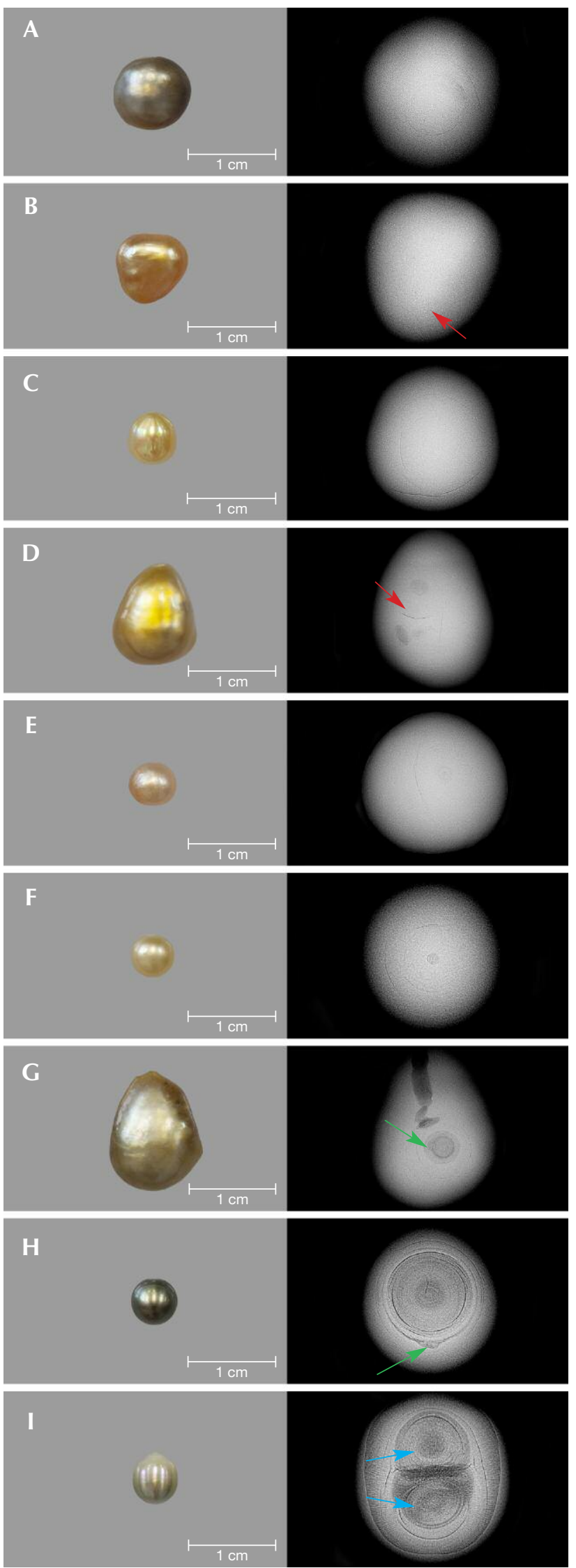
other components differ-the former is denser, while the latter are more transparent-allowing the internal structures to be viewed on the resulting images (Farn, 1986; Webster, 1994).

Microradiography was carried out on all the Pinctada maculata pearl samples and revealed clear natural pearl structures (Alexander, 1941; Farn, 1986; Taburiaux, 1986) in the majority. Growth arcs from the center toward the surface of the pearl, akin to the ring structure seen in onions or cross-sections of trees, together with faint organic-rich shadows positioned on the curves of some arcs, all typical of many natural pearls (figure 2, A-C), were present in most of the samples, although it is the authors' experience that some, such as pearl B, show a very faint structure (figure 2B, red arrow), which is also typical of natural pearls. Another commonly encountered structural feature of many natural pearls-a small dark radio-translucent, rounded organic-rich core-was also evident in the RTX results of many samples (figure 2, D-F). Another common feature in the way of a growth boundary was visible in the RTX results of pearl D (figure 2D, red arrow). Two organic-rich cores, one on each side of the boundary, were also visible. "Twins," or pearls formed of aggregates of pearls, are not uncommon in natural pearls from a number of species (Krzemnicki et al., 2010).

The last three pearls (figure 2, G-I) revealed internal structures with similarities to those that have been noted in pearls from Pinctada maxima and Pinctada radiata (Krzemnicki et al., 2010; Sturman et al., 2015) but differed from most of the other natural samples in the group we examined. Only these three pearls from the group exhibited such organicrich core structures. While the structures are likely natural, the minute whitish core in the center with some associated gaps between the concentric rings and the additional odd irregular white feature at the outer concentric rings or near the core of two of the pearls (figure 2, G-H, green arrows) raised some minor concerns about their identity (Sturman et al., 2016). The remaining pearl showed a twin structure (figure 2I, blue arrows) consisting of concentric organic-rich features with radial structures and a nearoval core in one part. While it is entirely possible for natural pearls such as this one to possess an unusually shaped core, it is the authors' experience that elliptical, drop, or other elongated core features are more often associated with non-bead-cultured pearls.

Among the group selected for examination was one blister/blister pearl ${ }^{1}$ attached to the valve of a Pinctada maculata shell (figure 3A). In keeping with many blisters/blister pearls, the preliminary observations of the RTX results showed the internal structure of the pearl "superimposed" with the growth features and imperfections of its host shell (figure 3B). The imperfections, found in the shells of most mollusk species, were present as veins or channels created by a living organism boring its way through the shell throughout its life. While it was unclear from initial observation whether this would be classified as a blister or a blister pearl, more detailed RTX analysis soon revealed that it was solid and possessed clear concentric rings more characteristic of a blister pearl than a blister (figure 3C).

Fluorescence Reactions. All the samples were examined under long-wave ultraviolet (LWUV) radiation. Their reactions varied in relation to their color saturation. Most of the darker samples were inert, while the lighter-color pearls and lighter-color areas on some of the more saturated pearls showed a moderate to strong chalky bluish green reaction. These fluorescence reactions are not diagnostic in any way and may be observed in pearls of similar saturations from other Pinctada species (Elen, 2001; Nilpetploy et al., 2018). Their reactions are also in keeping with naturally colored pearls and do not indicate the presence of any color treatment (Elen, 2001; Zhou et al., 2012).

Spectroscopic Results. Some of the Pinctada maculata pearl samples showing the most homogenous coloration were also selected for UV-Vis, Raman, and PL spectroscopic examination. Many were too small (approximately $3 \mathrm{~mm}$ or less) to examine with the external DRA of the UV-Vis and would have produced noisy spectra while potentially damaging the DRA's integrated sphere. Owing to the instrument's limitations and the generally smaller size of Pinctada maculata pearls, it was only possible to examine six samples with enough variation in their coloration with the UVVis spectrophotometer to show the results of the Raman and PL analyses. The spectral results directly corresponded with the color saturation and tone of the samples. The lighter samples showed higher reflectance values while the darker and more saturated ones exhibited less reflectance in the UV-Vis spectra.

\footnotetext{
${ }^{1} \mathrm{~A}$ blister is a structure that forms on the inside surface of a mollusk's shell and has the appearance of a pearl but is not a pearl by definition. A blister pearl forms in the body of a mollusk but for some reason moves to a position near the inside surface of a mollusk's shell. Layers of nacre are subsequently secreted over the pearl so that it becomes attached to the shell.
} 

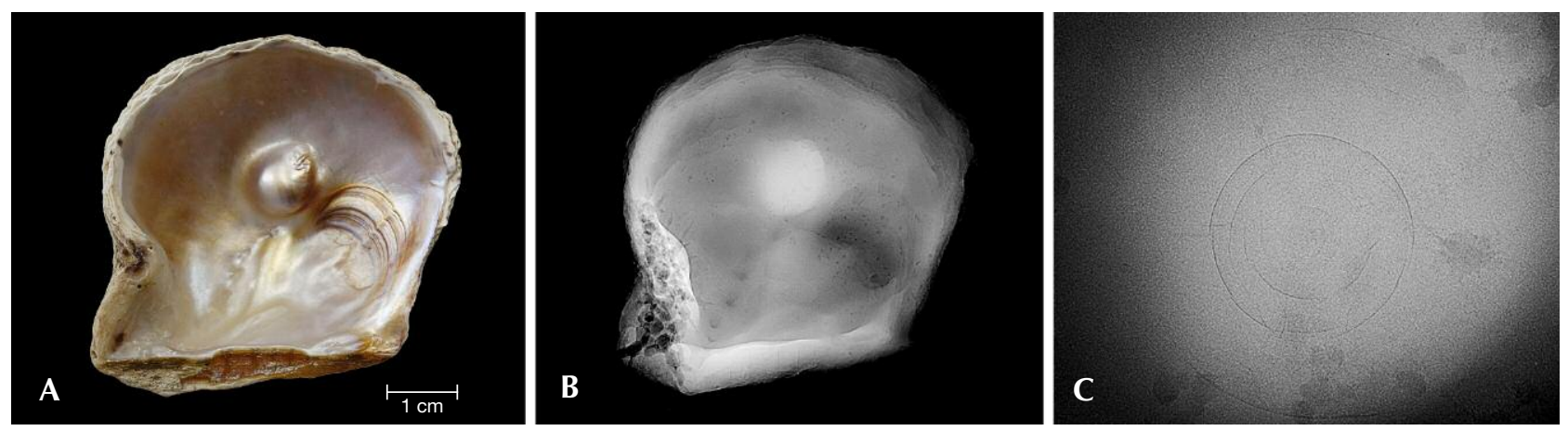

Figure 3. A blister pearl attached to its shell (A), measuring approximately $28.54 \times 26.50 \mathrm{~mm}$. Photo by Sasithorn Engniwat. RTX analysis revealed the shell with its blister/blister pearl (B), and when examined in more detail the blister pearl's internal structure $(C)$.

The UV-Vis spectra of the six pearls displayed a diffuse reflectance decrease between 330 and $460 \mathrm{~nm}$ (figure 4, blue shaded area), and four showed a clear feature at $495 \mathrm{~nm}$ (figure 4, indicated by a red dotted line) and a reflectance maximum between 550 and $720 \mathrm{~nm}$ (figure 4, green shaded area). Samples P590 and P593 did not show the $495 \mathrm{~nm}$ feature but did reveal a spectrum that differed from those of the other samples. In addition, a weaker feature around 445$455 \mathrm{~nm}$ was observed in P586 and P589. Other lightly colored pearl samples (white and light gray) were also examined. As expected, they did not exhibit any helpful features, so their spectra are excluded.

Raman spectra were collected for the same pearls (figure 5) in the same area tested when recording the
UV-Vis spectra, and as expected all showed the doublet peaks at $701,704 \mathrm{~cm}^{-1}$ attributed to the $v_{4}$ (inplane bending), a prominent peak at $1086 \mathrm{~cm}^{-1}$ attributed to the $\mathrm{v}_{1}$ (symmetric stretching), and weak features at 1464 and $1574 \mathrm{~cm}^{-1}$ attributed to the $\mathrm{v}_{3}$ (in-plane asymmetric stretching) of aragonite; the latter peak was recorded by previous authors (Urmos et al., 1991; Buzgar and Apopei, 2009). Furthermore, the spectra exhibited two small features at 1380 and $1540 \mathrm{~cm}^{-1}$ (figure 5, indicated by red dotted lines) most likely associated with pigments responsible for coloring the pearls. Samples P590 and P593 did not show any helpful features in their UV-Vis spectra (figure 4); however, two weak features were observed in the Raman spectra (figure 5). Other lightly colored

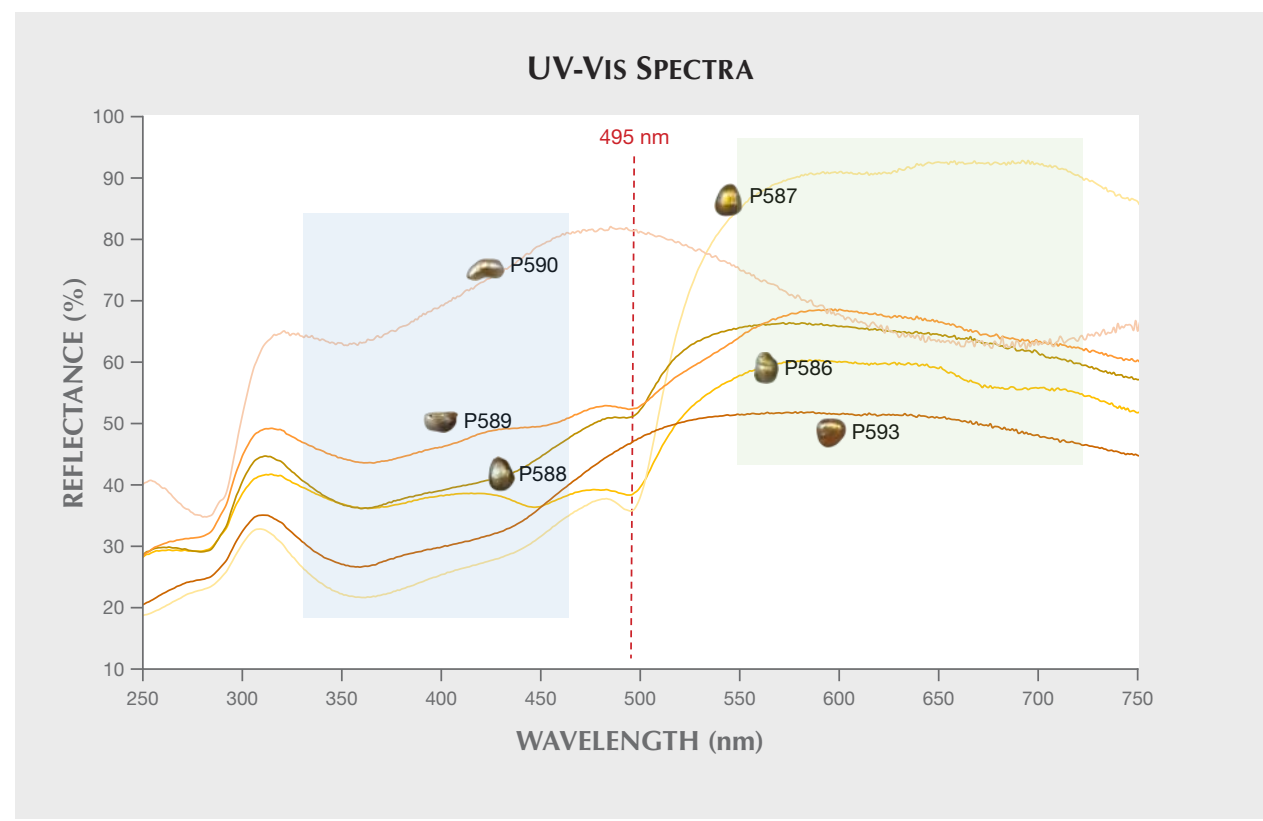

Figure 4. UV-Vis spectra of six Pinctada maculata samples. Four of the samples display a clear $495 \mathrm{~nm}$ feature (red dotted line). A diffuse reflectance decrease is also visible between 330 and 460 $\mathrm{nm}$ (blue shaded area), as well as a broad reflectance band around 550-720 nm (green shaded area). 




Figure 5. Raman spectra of six Pinctada maculata samples showing the aragonite-related peaks at 701, 704, 1086, 1464, and $1574 \mathrm{~cm}^{-1}$, with two additional features at 1380 and $1540 \mathrm{~cm}^{-1}$ (red dotted lines). The spectra were normalized and offset for clarity, each shifted upward by $30 \%$.

samples (white and light gray) were also tested, but as with the UV-Vis work, they did not show any helpful features either and therefore their spectra are excluded.
The PL spectra of four samples exhibited three broad peaks at approximately 620,650, and $680 \mathrm{~nm}$ (figure 6, indicated by red dotted lines). Additional peaks of varying intensity, most likely corresponding

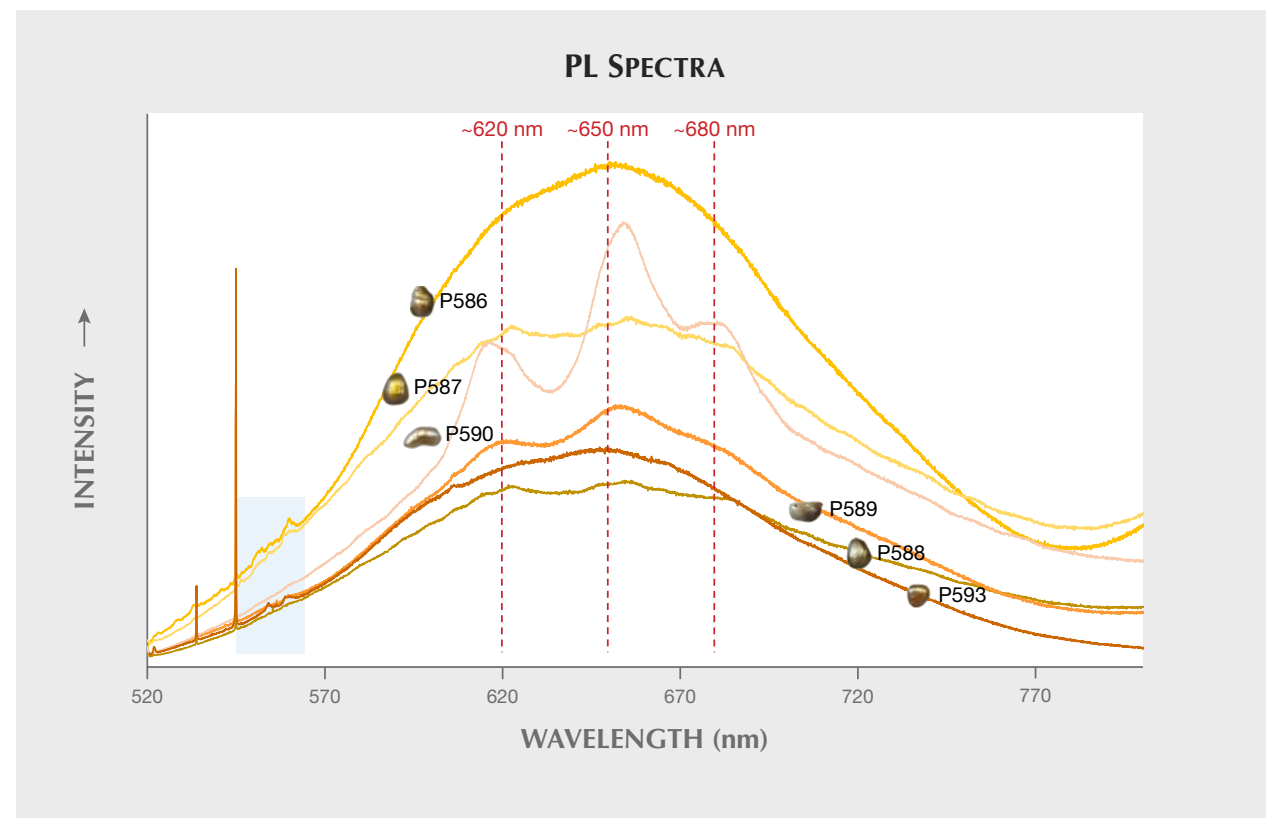

Figure 6. PL spectra of six Pinctada maculata samples showing the three broad peaks at approximately 620, 650, and $680 \mathrm{~nm}$ (red dotted lines), as well as a series of peaks between 545 and $565 \mathrm{~nm}$ (blue shaded area). The latter correspond to Raman peaks observed between 1106 and $1756 \mathrm{~cm}^{-1}$. 
TABLE 1. Comparison of features used in the separation of Pinctada maculata pearls from other mollusks.

\begin{tabular}{|c|c|c|c|c|}
\hline \multirow{2}{*}{ Mollusk } & \multicolumn{3}{|c|}{ Characteristic features } & \multirow{2}{*}{ References } \\
\hline & UV-Vis spectra $(\mathrm{nm})$ & Raman spectra $\left(\mathrm{cm}^{-1}\right)$ & PL spectra $(\mathrm{nm})$ & \\
\hline Pinctada maculata & $330-460,495$ & 1380,1540 & $\sim 620,650,680$ & This study \\
\hline Pinctada margaritifera & $\begin{array}{c}330-460 \text { (only in yellow), } \\
405,495,700\end{array}$ & $\begin{array}{l}\text { Bands between } 1100 \text { and } \\
1800\end{array}$ & $\sim 620,650,680$ & $\begin{array}{l}\text { Miyoshi et al. (1987); } \\
\text { Iwahashi and Akamatsu } \\
\text { (1994); Elen (2002); } \\
\text { Karampelas et al. (2011); } \\
\text { Homkrajae (2016); } \\
\text { Nilpetploy et al. (2018) }\end{array}$ \\
\hline Pinctada mazatlanica & $\begin{array}{c}330-460 \text { (only in yellow), } \\
405,700\end{array}$ & 1380,1540 (only in yellow) & $\sim 620,650,680$ & Homkrajae (2016) \\
\hline $\begin{array}{l}\text { Pteria penguin and } \\
\text { Pteria sterna }\end{array}$ & 405,495 & $\begin{array}{l}\text { Bands between } 1100 \text { and } \\
\qquad 1800\end{array}$ & $\sim 620,650,680$ & $\begin{array}{l}\text { Miyoshi et al. (1987); } \\
\text { Iwahashi and Akamatsu } \\
\text { (1994); Kiefert et al. (2004) }\end{array}$ \\
\hline $\begin{array}{l}\text { Pinctada maxima } \\
\text { (moderate to dark colors) }\end{array}$ & 495 & - & $\sim 620,650$, weak 680 & Karampelas (2012) \\
\hline $\begin{array}{l}\text { Pinctada maxima } \\
\text { (yellow color range) }\end{array}$ & $330-460$ & 1380,1540 & - & $\begin{array}{l}\text { Elen (2001); Cartier and } \\
\text { Krzemnicki (2016); GIA } \\
\text { reference pearls collected } \\
\text { from Jewelmer farms }\end{array}$ \\
\hline
\end{tabular}

to Raman peaks between 1106 and $1756 \mathrm{~cm}^{-1}$, were also observed between 545 and $565 \mathrm{~nm}$ (figure 6, blue shaded area) in all the spectra. Even though the bodycolor of sample P590 was lighter than the others, it still exhibited three obvious features in the PL spectra, but the UV-Vis spectra obtained from it were not helpful. The three bands in samples P586 and P593 were less prominent than noted in the other four pearls. As with the UV-Vis and Raman spectra collected from the white and light gray pearls, their lack of diagnostic features precluded their spectra from being included in this report.

The representative spectra from all the spectral methods, together with observation through a gemological microscope, did not reveal anything to indicate that the pearls were treated (i.e., color concentrations, veining, and patchiness via transmitted lighting), thus proving the natural color origin of the samples examined (Elen, 2001; Zhou et al., 2012).

\section{DISCUSSION}

The majority of pearl samples revealed natural structures, including three (figure 2, G-I) that exhibited more pronounced structures than the others. The concentric rings within the organic-rich core structures were very distinct and are similar to those of other natural pearls from Pinctada species examined in the laboratory. Such structures have, for example, been observed in both natural and non-bead-cultured Pinctada maxima pearls, with sufficient differences between the two to separate them in most cases (Sturman et al., 2015). However, since the samples in this study reportedly formed in a different mollusk species and their other gemological features (appearance and spectra) differ, it is more likely that these pearls too are natural and are not the challenging non-bead-cultured pearls that have been misrepresented as natural. Nevertheless, since the samples were not found by the authors in situ within a specific mollusk, other gemologists could disagree with the result based on their interpretation of the structures. On the other hand, the natural blister pearl attached to the valve of a Pinctada maculata specimen was from the same source as the other samples, providing a degree of assurance that their claimed origin is the same. The authors failed to find any published record of non-bead-cultured pearls from Pinctada maculata mollusks. Therefore, the data we obtained indicates that the samples in this study likely formed within Pinctada maculata mollusks.

The spectroscopic work revealed features consistent with those observed for naturally colored pearls from various Pinctada species mollusks, including Pinctada maculata (table 1). The UV-Vis reflectance spectra results provide the most helpful features to indicate that the pearls possibly originated from Pinctada maculata, including a clear $495 \mathrm{~nm}$ feature in most of the samples. However, this feature has also been recorded in some naturally colored pearls from other mollusks such as Pinctada margaritifera 
(Elen, 2002; Karampelas et al., 2011), Pteria penguin (Miyoshi et al., 1987; Iwahashi and Akamatsu, 1994), and Pteria sterna (Kiefert et al., 2004), often in association with a feature at $405 \mathrm{~nm}$ that is reportedly related to uroporphyrin protein (Iwahashi and Akamatsu, 1994). Moreover, previous research also reports that the $495 \mathrm{~nm}$ feature is present in moderate to dark Pinctada maxima cultured pearls covering a range of colors (Karampelas, 2012).

While most Pinctada maculata samples display the $495 \mathrm{~nm}$ feature, they do not show other features at 405 and $700 \mathrm{~nm}$. This could provide a way to separate them from pearls that form in Pinctada margaritifera, Pinctada mazatlanica, Pteria penguin, and Pteria sterna mollusks.

Furthermore, the diffuse reflectance decrease around $330-460 \mathrm{~nm}$ in most samples is similar to that seen in naturally colored yellow pearls from Pinctada maxima (Elen, 2001), Pinctada margaritifera (Elen, 2002), and Pinctada mazatlanica (Homkrajae, 2016). When comparing the UV-Vis spectra of yellow Pinctada maculata with Pinctada maxima, Pinctada margaritifera, and Pinctada mazatlanica pearls (figure 7), some similarities are evident between some samples, yet differences that may allow separation also exist. The $495 \mathrm{~nm}$ feature (figure 7, indicated by a red dotted line) usually appears to be fairly pronounced in Pinctada maculata pearl. It is not present in Pinctada maxima or Pinctada mazatlanica samples, while Pinctada margaritifera pearl shows the feature to varying degrees depending on its color, tone, and saturation. Unlike the other mollusks, nearly all Pinctada margaritifera and Pinctada mazatlanica pearls show the $700 \mathrm{~nm}$ feature, which helps differentiate them from the other Pinctada species.

The majority of Pinctada maculata samples show two features at 1380 and $1540 \mathrm{~cm}^{-1}$ in their Raman spectra. Similar features have also have been recorded in naturally colored yellow Pinctada maxima pearls (Cartier and Krzemnicki, 2016). Moreover, based on prior experience when compared with known naturally colored "golden" Pinctada maxima pearls sourced directly from Jewelmer's pearl farms (internal GIA research, unpublished results), these features are typically present in pearls of both species, and in those of Pinctada mazatlanica with a yellow component, but they are not recorded in pearls of a yellow hue range from other mollusk species. The specific cause of these features is unknown, and their positions do not exactly match with other known color pigments recorded (Karampelas et al., 2009; Bergamonti et al., 2011; Zhou and Dzikowski, 2015; Cartier and Krzemnicki, 2016). While the features around $1540 \mathrm{~cm}^{-1}$ show some similarity to the Raman peak recorded in freshwater pearls attributed to polyenic proteins (Soldati et al., 2008), the pearls from this study are saltwater, and therefore the features' relevance is questionable since the positions do not match exactly.

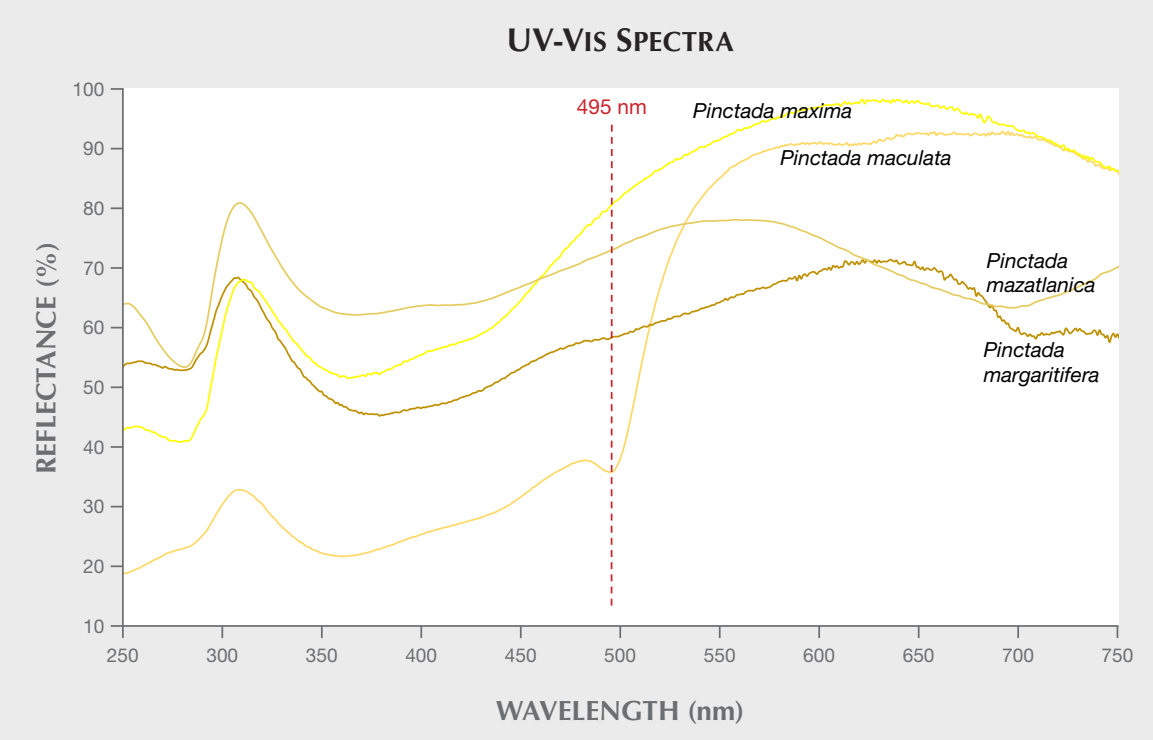

Figure 7. Comparative UV-Vis spectra of four yellow Pinctada maxima, Pinctada maculata, Pinctada mazatlanica, and Pinctada margaritifera pearls showing some spectral features that help distinguish them from one another. 
The three PL spectral features at approximately 620,650 , and $680 \mathrm{~nm}$ have been recorded in naturally colored pearls, usually with moderate to darker tones and saturations, from Pinctada maxima (Karampelas, 2012), Pinctada margaritifera (Nilpetploy et al., 2018), Pinctada mazatlanica (Homkrajae, 2016), Pteria penguin (Miyoshi et al., 1987; Iwahashi and Akamatsu, 1994), and Pteria sterna (Kiefert et al., 2004). The peak around $620 \mathrm{~nm}$ is reportedly associated with the uroporphyrin protein (Iwahashi and Akamatsu, 1994). A Pinctada maculata blister pearl sample (again, see figure 3) was also subjected to spectroscopic analysis. The PL spectrum of the blister pearl showed the same three features referred to above, indicating a natural coloration. The Raman results were not so helpful, probably because of the sample's light color, while a useful UV-Vis spectrum could not be obtained owing to the limitation of the specimen's shape.

\section{CONCLUSIONS}

Pipi pearls found in Pinctada maculata mollusks are almost always natural since successful cultivation using this mollusk has never been documented, and the authors are aware of no such commercial products in the market. Even though Pinctada maculata pearls are small, owing to the mollusk being the smallest member of the Pinctada genus, their color range is desirable enough to warrant interest, and it is not inconceivable that future technology might permit commercial quantities of cultured pearls to be produced one day. Unfortunately, the mollusk's population is limited in comparison to economic species such as Pinctada maxima or Pinctada margaritifera mollusks. Pinctada maculata's small size and limited geographical habitat may make investment in any culturing venture unlikely.

The internal structures found in this study did not reveal evidence of any culturing, and virtually every sample showed structures routinely observed within natural pearls from a wide variety of mollusks. It would not be possible to conclude that a pearl formed within a Pinctada maculata mollusk based only on its structure, but there could be strong indications that a pearl originated from the mollusk if its internal structure, external appearance, and spectral characteristics were all taken into account and met the relevant criteria. For example, pearl P587 (figure 2D) shows a distinct uneven yellow color that may be observed for either
Pinctada maculata or Pinctada maxima pearls; however, there are some brownish yellow areas and its size is also small, under $6 \mathrm{~mm}$, which is more toward Pinctada maculata pearls. Moreover, its UV-Vis spectra (the presence of the $495 \mathrm{~nm}$ feature in particular), PL spectrum (a weak three-peak pattern), and small dark organic core (albeit a twincore pearl with a boundary) all strongly suggest that it was recovered from a Pinctada maculata mollusk. Samples P606 and P609 (figure 2, E-F) also show small organic cores more typical of yellow to orange pearls that form in Pinctada maculata mollusks, but they were too small to obtain UV-Vis spectra. However, their PL spectra did show the three bands seen in other Pinctada maculata pearls of similar colors and not the pattern seen in comparable Pinctada maxima pearls. Most natural Pinctada maculata pearls are colored and smaller than natural or non-bead-cultured Pinctada maxima pearls, and this may assist to some extent in separating them.

Although the spectroscopic results of some of the Pinctada maculata samples revealed characteristic features that help in some respects with their mollusk identification (e.g., sample P587), they also shared other features in common with other mollusk species such as Pinctada maxima, Pinctada margaritifera, Pteria penguin, and Pteria sterna. Therefore, no definitive information can be gleaned from the spectra of Pinctada maculata pearls that will guarantee their separation from other mollusk species, so other factors such as external appearance and internal structures must also be considered. Since mollusks of the Pinctada genus and Pteria genus are members of the Pteriidae family, it is not surprising that they share some common traits with respect to composition, appearance, and spectral characteristics. While some of these traits may not be precise matches, they still provide useful criteria with which to make a well-reasoned conclusion on the identity of the mollusk that produced a specific pearl.

Further study of known Pinctada maculata pearls and their mollusks, ideally sourced directly from the ocean, would be the best option to enforce the findings provided by samples we believed to be from the same mollusk. In order to make the findings even more comprehensive, the full structural and spectroscopic details of natural pearls from other known mollusks (e.g., Pinctada and Pteria species) ideally should be studied and compared. 
ABOUT THE AUTHORS

Ms. Nilpetploy (née Somsa-ard) is a staff gemologist, and Ms. Lawanwong and Mr. Kessrapong are analytics technicians, in pearl services at GIA in Bangkok.

\section{ACKNOWLEDGMENTS}

The authors would like to thank GIA colleagues in Bangkok, New York, and Carlsbad for their valuable assistance. Suggestions from two anonymous peer reviewers and Elisabeth Strack, the third peer reviewer, to improve the content are also greatly appreciated.

\section{REFERENCES}

Alexander A.E. (1941) Natural and cultured pearl differentiation. $G \uplus G$, Vol. 3, No. 12, pp. 184-187.

Bergamonti L., Bersani D., Csermely D., Lottici P.P. (2011) The nature of the pigments in corals and pearls: A contribution from Raman spectroscopy. Spectroscopy Letters, Vol. 44, No. 7-8, pp. 453-458, http://dx.doi.org/10.1080/00387010.2011.610399

Buscher E. (1999) Gem News: Natural pearls from the northern Cook Islands. $G \uplus G$, Vol. 35, No. 2, pp. 147-148.

Buzgar N., Apopei A. (2009) The Raman study of certain carbonates. Geologie. Tomul LV, No. 2, pp. 97-112.

Cartier L.E., Krzemnicki M.S. (2016) Golden South Sea cultured pearls: cultivation steps \& gemological investigations. The Journal of the Gemmological Association of Hong Kong, Vol. 37 , pp. 16-21.

CIBJO International Jewellery Confederation (2016) The Pearl Book. CIBJO Pearl Commission, p. 41.

Elen S. (2001) Spectral reflectance and fluorescence characteristic of natural-color and heat-treated "golden" South Sea cultured pearls. $G \nrightarrow G$, Vol. 37, No. 2, pp. 114-197, http://dx.doi.org/ 10.5741/GEMS.37.2.114

Elen S. (2002) Identification of yellow cultured pearls from the black-lipped oyster Pinctada margaritifera. $G \uplus G$, Vol. 38, No. 1, pp. 66-72, http://dx.doi.org/10.5741/GEMS.38.1.66

Farn A.E. (1986) Pearls: Natural, Cultured and Imitation. Butterworths Gem Books, United Kingdom.

GIA Pearl Grading Color Reference Charts (2000) Gemological Institute of America, Carlsbad, CA.

Gould A.A. (1846) On the shells collected by the United States Exploring Expedition under the command of Charles Wiles. Proceedings of the Boston Society of Natural History, Vol. 2, pp. 141-145.

Homkrajae A. (2016) Gem News International: Spectral characteristics of Pinctada mazatlanica and Pinctada margaritifera oyster species. $G \uplus G$, Vol. 52, No. 2, pp. 207-208.

Iwahashi Y., Akamatsu S. (1994) Porphyrin pigment in black-lip pearls and its application to pearl identification. Fisheries Science, Vol. 60, No. 1, pp. 69-71, http://dx.doi.org/10.2331/fishsci.60.69

Karampelas S. (2012) Spectral characteristics of natural-color saltwater cultured pearls from Pinctada maxima. Ge G, Vol. 48, No. 3, pp. 193-197, http://dx.doi.org/10.5741/GEMS.48.3.193

Karampelas S., Fritsch E., Mevellec J.-Y., Sklavounos S., Soldatos T. (2009) Role of polyenes in the coloration of cultured freshwater pearls. European Journal of Mineralogy, Vol. 21, No. 1, pp. 85-97, http://dx.doi.org/10.1127/0935-1221/2009/0021-1897

Karampelas S., Fritsch E., Gauthier J.-P., Hainschwang T. (2011) UV-Vis-NIR reflectance spectroscopy of natural-color saltwater cultured pearls from Pinctada margaritifera. GÆ G, Vol. 47, No. 1, pp. 31-35, http://dx.doi.org/10.5741/GEMS.47.1.31

Kessrapong P., Lawanwong K., Sturman N. (2017) Pinctada maculata (Pipi) bead-cultured blister pearls attached to their shells. Research News, https://www.gia.edu/gia-news-research/pinctadamaculata-bead-cultured-blister-pearls-shells.

Kiefert L., Moreno D.M., Arizmendi E., Hänni H., Elen S. (2004) Cultured pearls from the Gulf of California, Mexico. $G \uplus G$,
Vol. 40, No. 1, pp. 26-38, http://dx.doi.org/10.5741/GEMS. 40.1 .26

Krzemnicki M. (2014) Pipi pearls from the Pacific. Facette, No. 21 p. 20.

Krzemnicki M., Friess S.D., Chalus P., Hänni H.A., Karampelas S. (2010) X-ray computed microtomography: Distinguishing natural pearls from beaded and non-beaded cultured pearls. $G \oplus G$ Vol. 46, No. 2, pp. 128-134, http://dx.doi.org/10.5741/GEMS 46.2.128

Miyoshi T., Matsuda Y., Komatsu H. (1987) Fluorescence from pearls and shells of black lip oyster, Pinctada margaritifera, and its contribution to the distinction of mother oysters used in pearl culture. Japanese Journal of Applied Physics, Vol. 26, No. 7, pp. 1069-1072, http://dx.doi.org/10.1143/JJAP.26.1069

Nilpetploy N., Lawanwong K., Kessrapong P. (2018) Non-bead-cultured pearls from Pinctada margaritifera. Research News, https://www.gia.edu/gia-news-research/non-bead-culturedpearls-from-pinctada-margaritifera.

Passfield K. (1997) Notes on 'pipi' pearl oyster, Pinctada maculata, fishing in Tongareva, Cook Islands, 1995. SPC Pearl Oyster Information Bulletin \#10, August 1997, pp. 21.

Segura O., Fritsch E., Touati D. (2014) Gem News International: Natural pipi pearls from Tahiti. Gせ G, Vol. 50, No. 1, pp. 89-90.

Soldati A.L., Jacob D.E., Wehrmeister U., Häger T., Hofmeister W. (2008) Micro-Raman spectroscopy of pigments contained in different calcium carbonate polymorphs from freshwater cultured pearls. Journal of Raman Spectroscopy, Vol. 39, No. 4, pp. 525536, http://dx.doi.org/10.1002/jrs.1873

Southgate P.C., Lucas J.S. (2008) The Pearl Oyster. Elsevier, Oxford, United Kingdom, p. 279.

Strack E. (2006) Pearls. Rühle-Diebener-Verlag, Stuttgart, Germany. Sturman N., Homkrajae A., Manustrong A., Somsa-ard N. (2015) $\mathrm{X}$-ray computed microtomography ( $\mu-\mathrm{CT})$ structures of known natural and non-bead cultured Pinctada maxima pearls. Proceedings of the 34th International Gemmological Conference IGC, Vilnius, Lithuania, pp. 121-124.

Sturman N., Manustrong A., Pardieu V. (2016) The cultured pearls of Mergui with an emphasis on their internal structures. Proceedings: The 5th GIT International Gem and Jewelry Conference, Pattaya, Thailand, pp. 143-144.

Taburiaux J. (1986) Pearls: Their Origin, Treatment and Identification. Chilton Book Co., Radnor, PA.

Urmos J., Sharma S.K., Mackenzie F.T. (1991) Characterization of some biogenic carbonates with Raman spectroscopy. American Mineralogist, Vol. 76, pp. 641-646.

Webster R. (1994) Gems: Their Sources, Descriptions and Identification. 5th ed., rev. by P.G. Read, Butterworth-Heinemann, Oxford, United Kingdom.

Zhou C., Homkrajae A., Ho J.W.Y., Hyatt A., Sturman N. (2012) Update on the identification of dye treatment in yellow or "golden" cultured pearls. Ge G, Vol. 48, No. 4, pp. 284-291, http://dx.doi.org/10.5741/GEMS.48.4.284

Zhou W., Dzikowski T. (2015) Species identification and treatment detection in dark coloured pearls. Swiss Geoscience Meeting 2015, Basel, Switzerland, pp. 134-135. 